\title{
LUT
}

Lappeenranta

University of Technology

\section{Experimentation on Wind Powered Hydraulic Heating System}

Roozbahani Hamid, Ikechukwu Kingsley Chima, Ăman Rafael, Handroos Heikki

This is a Final draft

version of a publication

published by IEEE

in IEEE Global Fluid Power Society Symposium 2018

DOI: $\quad 10.1109 /$ GFPS.2018.8472396

Copyright of the original publication: (C) IEEE 2018

Please cite the publication as follows:

Roozbahani H., Ikechukwu Kingsley C., Ăman R., Handroos H. (2018). Experimentation on Wind Powered Hydraulic Heating System. IEEE Global Fluid Power Society Symposium 2018. DOI:

10.1109/GFPS.2018.8472396 


\title{
Experimentation on Wind Powered Hydraulic Heating System
}

\author{
Hamid Roozbahani ${ }^{*}$, Ikechukwu Kingsley Chima ${ }^{2}$, Rafael Åman ${ }^{3}$, Heikki Handroos ${ }^{4}$ \\ 1,2,3,4 Lappeenranta University of Technology, Lappeenranta, Finland \\ *Corresponding Author: hamid.roozbahani@lut.fi, +358 (40) 678 394, \\ Lappeenranta University of Technology, P.O.Box 20, FI-53851 Lappeenranta, Finland
}

\begin{abstract}
It is common knowledge of the world's dependency on fossil fuel for energy, its unsustainability on the long run and the changing trend towards renewable energy as an alternative energy source. This aims to cut down greenhouse gas emission and its impact on the rate of ecological and climatic change. Quite remarkably, wind energy has been one of many focus areas of renewable energy sources and has attracted lots of investment and technological advancement. The objective of this research is to explore wind energy and its application in household heating. This research aims at applying experimental approach in real time to study and verify a virtually simulated wind powered hydraulic house heating system. The hardware components comprise of an integrated hydraulic pump, flow control valve, hydraulic fluid and other hydraulic components. The system design and control applies hardware in-the-loop (HIL) simulation setup. Output signal from the semi-empirical turbine modelling controls the integrated motor to generate flow. Throttling the volume flow creates pressure drop across the valve and subsequently thermal power in the system to be outputted using a heat exchanger. Maximum thermal power is achieved by regulating valve orifice to achieve optimum system parameter. Savonius rotor is preferred for its low inertia, high starting torque and ease of design and maintenance characteristics, but lags in power efficiency. A prototype turbine design is used; with power output in range of practical Savonius turbine. The physical mechanism of the prototype turbine's augmentation design is not known and will not be a focus in this study.
\end{abstract}

Keywords-Savonius Rotor, Tip speed ratio, Torque coefficient, Fluid power circuit, Throttle valve, Optimum orifice diameter, Thermal power

\section{INTRODUCTION}

This research is a continuation on "Virtually Simulated Hydraulic House Heating Model" research [1]. Via experimentation, a motor controlled to mimic a wind turbine is coupled to a novel hydraulic house heating system and utilized to study the energy conversion of wind energy into heat for house heating purpose. This approach of energy conversion to heat stems from the need to improve the efficiency of energy output and reduction of losses that accrue in wind to electrical energy conversion.

Savonius rotor is adopted as the test rotor for its low inertia, high starting torque in low wind, ease of design and maintenance characteristics. A prototype Savonius turbine model [2] was used and power achieved is in range of practical Savonius turbine power output. However, no information about the physical mechanism of the turbine's augmentation design was made available by the source.

Wind has been one of many useful energy sources other applications other than power generation such as in grinding mills and irrigation purposes. The level of investment and technological development $[3,4,5]$ in alternate power sources indicates an increasing interest over time in wind and other renewable energy applications for power generation.
This is due to their sustainability, clean energy and availability for most part of the year. Wind energy is one of the key energy sources have providing alternative to fossil fuel but at a cost. To this end, technologies have been developed to harness this energy and more research is underway to optimize the efficiency of energy output from wind.

The idea of a compact and simple system design with Savonius rotor is aimed at solving the bulk nature of the widely used horizontal-axis wind turbine (HAWT). HAWT turbine hardware comprise of the following major components - rotor, nacelle (gearbox and generator), blades, tower and transformer [6, 7]. By adopting Savonius turbine, the system eliminates the need for a drivetrain, generator and heavy towers required to support HAWT turbine's weight while cutting down on costs incurred in power generation from wind energy.

The system design applies hardware in-the-loop (HIL) simulation setup. In HIL simulation, the virtually simulated system is operated in real-time with its simulated dynamic equivalent [8]. Application of HIL simulation is on the increase in model validation and testing by replacing parts of a simulation model of a system with hardware components. The flexibility HIL simulation offers in application to wide operating conditions improves reliability and better understanding of system interaction [9].

The turbine model is designed using mathematical equations of a typical Savonius rotor. The virtual turbine simulation integrated in the setup controls the output power of the electric motor connected in the setup. Signal response measured from hardware components are inputted into the simulation in real time.

The experimental set-up is an open-loop hydraulic circuit using an Integrated Electro-Hydraulic Energy Converter (IEHEC) as power source. The system comprises of an integrated electrical motor and a hydraulic pump, controlled using the inverter to mimic the dynamic behavior of wind turbine. The motor actuates the pump to produce the required volume flow in the system. Sets of valve; a pressure relief valve is mounted in the set-up to regulate pressure buildup as a safety measure. To constrict flow, a pin valve is used thereby generating heat in the hydraulic fluid. The heat generated is then outputted using a heat exchanger for useful house heating. The experimental result will be compared with the results of the virtually simulated turbine model [1] from earlier study. The potential for this system is aimed for application in remote sites; hence easy of assembly and compactness are factors to consider in commercial design. Unlike in electrical power generation systems, access to the grid and frequency conversion mechanism are eliminated thereby avoiding need of transmission, high equipment costs and losses incurred. Direct heat conversion of wind energy is aimed at curtailing losses and improving the efficiency of wind energy conversion. 


\section{A. Background information}

Application of hydraulic systems for energy generation is rather not a new field of study. As far back as June of 1977, a patent was registered of a system utilizing wind powered hydraulic heating system. This invention uses a wind velocity sensor and a valve control mechanism responsive to the sensor to control an adjustable pressure responsive relief valve which restricts the flow of hydraulic fluid thereby generating heat The sensor; a mechanical lever wind gauge coupled to the relief valve controls the valve opening with respect to the wind speed. Similar mechanism responsive to valve inlet pressure is utilized to close the valve with changing wind speed [10].

A different experimental study [11] utilizing hydraulic throttling for domestic heating recorded an achieved room temperature heating up to $70^{\circ} \mathrm{C}$ within 15 minutes. The outlined projects and many other researches in the field indicate growing interest in thermal energy generation using hydraulic system. This project serves the purpose of studying thermal power generation from a hydraulic circuit driven by wind energy. Similar to the projects mentioned in [5] and [6], it differs in the source of the driving power and type of valve used. The optimum operating condition of the experimental systems will be noted. The experiment explores the virtual simulation guidelines. Results are to be corroborated and recommendation for improvement offered where possible. Calculated power values from the wind data is tabulated in the result section.

The systems' components comprise of a frequency converter controlled IEHEC motor which serves as the primary power source of the hydraulic circuit; mimicking the behavior of a wind rotor with defined operating parameter of a typical Savonius rotor subject to different wind speed. Other vital components of the hydraulic circuit are the flow control and pressure relief valves for flow constriction and regulation of system maximum set-point pressure respectively. At a set orifice area, oil flow is constricted creating pressure drop across the flow control valve. The heat generated is to be outputted to the surrounding using an oilto-air cooler. Hydraulic tank and piping in the set-up serve the purpose of storing and transporting the hydraulic fluid. More so the tank would serve as a heat reservoir for the undissipated heat in the returning hydraulic fluid. Tank capacity and heat loss to the environment are factor not accounted for in this study. Hence an ideal adiabatic and leakage free system set-up is considered. It should be noted that of special interest in this research is the efficiency of performance of the throttle valve and parameters of the turbine and valve at which thermal power output is optimal. To demonstrate commercial application of the system, Fig. 1 shows the system's component assembly. It is worth noting that hydraulic house heating system is not limited to Savonius rotor, however in this study, Savonius rotor is the primary drive system harnessing the wind energy.

\section{B. Objectives and scope of research problem}

The objective of this research work is to verify the results of the virtually simulated model using practical experiment and the possible commercialization of the system given a viable result from the experiment. Steps will be taken to improve the efficiency of thermal power generation by studying the behavior of the flow control valve (throttle valve) unit in more detail by comparing the measured flow characteristics of the valve in the set-up with that provided by the manufacturer.

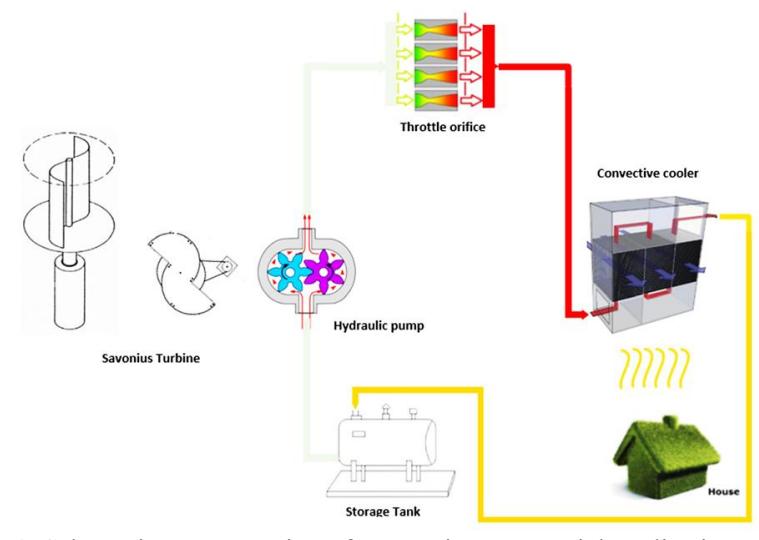

Fig. 1. Schematic representation of system in commercial application.

The result is aimed at validating the semi-empirical approach applied in valve modelling in the experiment.

The valve in question is a needle valve which operates by manual adjustment to a desired set point. Going by the output result of the virtual simulation model, the maximum power is achieved when the orifice diameter was adjusted as such that the rotor tip speed ratio follows the power curve [1]. Hence a proportional valve could best be used to achieve this self- adjustment for operation at optimum tip speed ratio of the turbine. This will require to consider the energy requirement. However, use of proportional valve is beyond the scope of this research. In other words, an optimum valve orifice should be applied for the valve in use.

In the previous research, a measured wind speed was applied. This wind data was gathered by Finnish meteorological institute. The power output of the virtual turbine - and subsequently the thermal power output at average wind speed is in the range of 100-1000 W. For real-time simulation with the experimental set-up, a sample wind profile of constant wind speed (in range of $2 \mathrm{~m} / \mathrm{s}$ to 12 $\mathrm{m} / \mathrm{s}$ ) over a time period was designed and used to study the system response.

The IEHEC motor offered a flexible and efficient substitute to the Savonius rotor. The parameters of a typical augmented Savonius rotor was used to harness the wind energy thereby driving the pump. More details of the rotor model and other physical components used in the system build-up will be discussed in Chapter 2 of this document.

\section{Research methodology}

The research employs an experimental approach to evaluate the result of a simulated wind turbine and hydraulic transmission system. The simulation applied semiempirical modelling of physical components that made up the hydraulic transmission and Savonius turbine systems. Matlab graphical interface (Simulink) is used for modelling and simulation.

The experiment made use of commercially available hardware components as shown assembled in Fig. 1. Virtual simulation model of turbine is used to control the input rotational speed of the IEHEC motor. In practice, some of the input variables to the simulated model, such as pressure and flow rate are measured signals from the physical sensors in the experimental set-up. The results of the experiment will be compared to that of the virtual simulation model. A plot of the turbine tip speed ratio and torque coefficient will outline the conformity and concurrence of the models while taking into account the assumptions and approximations used during modeling. 
The virtual turbine model is compiled and run in real time interface of ControlDesk software (dSPACE-DS1005). The real time interface (RTI) feeds the operating parameters of the turbine to the inverter, and subsequently control the rotational speed of the IEHEC motor. Similarly, outputs from the set-up such as the pressure, temperature and volume flow of the pump are measured. The interconnectivity of the physical set-up and the ControlDesk is made possible by use of an analog to digital (ADC) and digital to analog (DAC) board for signal processing.

The experiment was carried out by initially operating the IEHEC motor at constant speeds while varying the valve orifice area over a fixed time period. By so doing, the temperature, pressure, flow rate and thermal power of the system were evaluated. Documentation and evaluation of the experimental results is outlined in the following Chapters. Of interests are pressure build up with changing wind speed in proportion to varied valve orifice area, thermal power of the system, flow characteristics of the valve and efficiency of the turbine. Figure 2 shows a schematic arrangement of the system set-up.

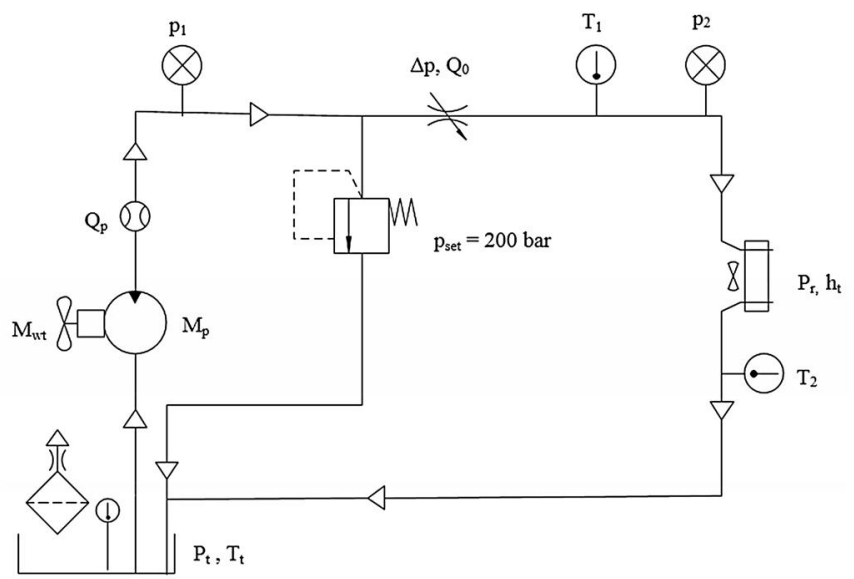

Fig. 2. Schematics of assembly of system Hardware components

\section{Organization of the study}

The outline of this paper is as follows. In the second Chapter, the system components are introduced together with mathematical models used in system set-up. In Chapter 3 , the turbine models will be reviewed. Modification to the virtual simulation model, experimental set-up and the measurement procedure will be explained. Following the measurement procedure are result tabulation and analysis in the fourth Chapter. Finally, the conclusion is drawn together with recommendations.

\section{COMPONENT DISCRIPTION AND DIMENSIONING}

This section discusses in brief the component description, dimensioning and parametric equations used in modelling the output responses of the input parameters to these components.

\section{A. Savonius turbine model}

The aerodynamic energy of wind is a function of the mass flow rate and rate of change in the kinetic energy $E$ of wind [12].

$\dot{m}=\rho A v$
$E=0.5 m_{w} v^{2}$

where $m_{w}$ is wind, $v$ is the wind velocity, $p$ density of the wind, $A$ turbine cross-sectional area and $E$ is the kinetic energy of wind. From equations $(1 \& 2)$, wind power $\left(P_{w}\right)$ [12] is derived.

$P_{w}=\dot{m} \frac{d E}{d t}=\frac{1}{2} \rho A v^{3}$

where $\frac{d E}{d t}$ is the rate of change in the kinetic energy of wind. Equation (3) gives power contained in wind moving across the turbine's cross-sectional area. Betz Criterion [13] presents an ideal wind energy conversion efficiency of a wind turbine. The limit stands at a maximum of $59 \%$. In practice, this efficiency level is hardly achieved as is visible in the Fig. 3.

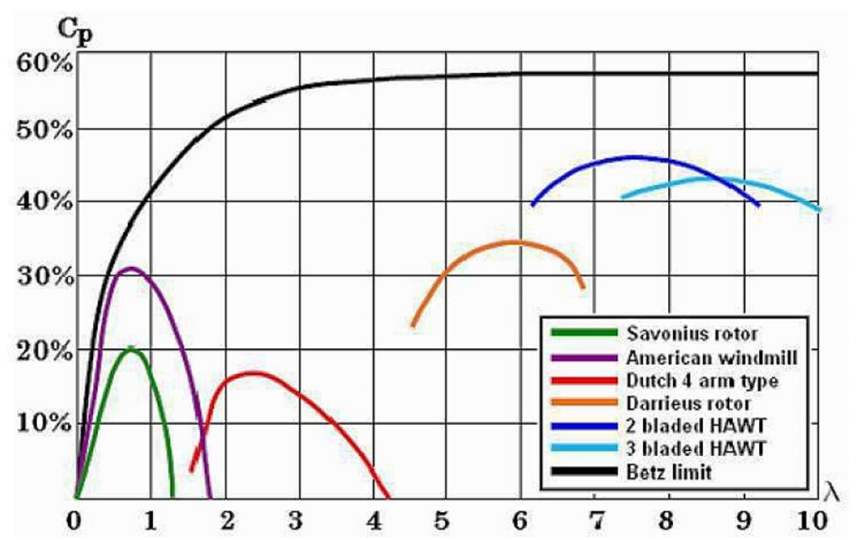

Fig. 3. Power coefficient $(\mathrm{Cp})$ versus Tip speed ratio $(\lambda)$ of various Wind Turbines [17].

The power coefficient $\left(C_{p}\right)[14,15]$, which is dependent on the tip speed ratio of the rotor, is used to determine the efficiency of the turbine. A realistic $C_{p}$ value lies between $(0.35-0.40) \%$ for practical wind turbines [13]. The power output of any wind turbine is a function of its power coefficient. Turbine power $\left(P_{w t}\right)$ [12] is deduced.

$P_{w t}=C_{p} P_{w}=M_{w t} \omega$

where $M_{w t}$ is turbine output torque and $w$ is the angular velocity of the rotor. Hence turbine output torque $M_{w t}$ is derived as follows: Power coefficient $\left(C_{p}\right)$ of a turbine is dependent on the turbine's tip speed ratio $(\lambda)$ [16]. This relationship is given by

$C_{p}=\frac{M_{w t} \omega}{\frac{1}{2} \rho A v^{3}}=C_{t} \lambda$

where $\lambda$ is tip speed ratio and $C_{t}$ is torque coefficient and $M_{w t}$ is the turbine output torque. The system torque is defined by

$M_{w t}=0.5 \rho C_{t}(\lambda) v^{2} A r$

Tip speed ratio which is the ratio of the blade speed to free stream wind speed across the blade [16] is given by

$\lambda=\frac{\omega r}{v}$ 
Of these turbines, Savonius rotor was chosen due to its high self-starting torque at low rotor speed [18]. This characteristic of the rotor makes for good application in low wind speed area.

Due to low power efficiency of the Savonius rotor; with typical power coefficient in range of $(12-15) \%$ and tip speed ratio $(\lambda)$ of $0.7 \%$ [19], different research has been carried out to this effect to improve performance. Further experimental studies carried out on Savonius rotor has been documented showing efficiency improvement ranging from $20 \%$ to $35 \%[20,21]$ corresponding to an optimal tip speed ratio of about 0.95 .

The variations in power coefficient arise from modification to geometrical parameters of conventional Savonius rotor [22]. By method of extrapolation and closed jet wind tunnel testing, optimum power coefficient of $32 \%$ has been achieved with modification in conventional Savonius rotor having central shaft. Similarly, power coefficient of $21 \%$ has been documented in an open wind jet tunnel study of a Savonius rotor with a central shaft design modification [23]. Hence one can observe a significant impact on power output of the turbine with geometrical modification and test environment.

By applying known torque coefficient parameter of conventional wind turbine, the power coefficients and consequently power outputs of the turbine could be evaluated. Parameters of a prototype Savonius rotor was used to model a practical Savonius rotor for the experiment. Figure 4 shows torque coefficient and tip speed ratio relationship of Savonius turbine models.

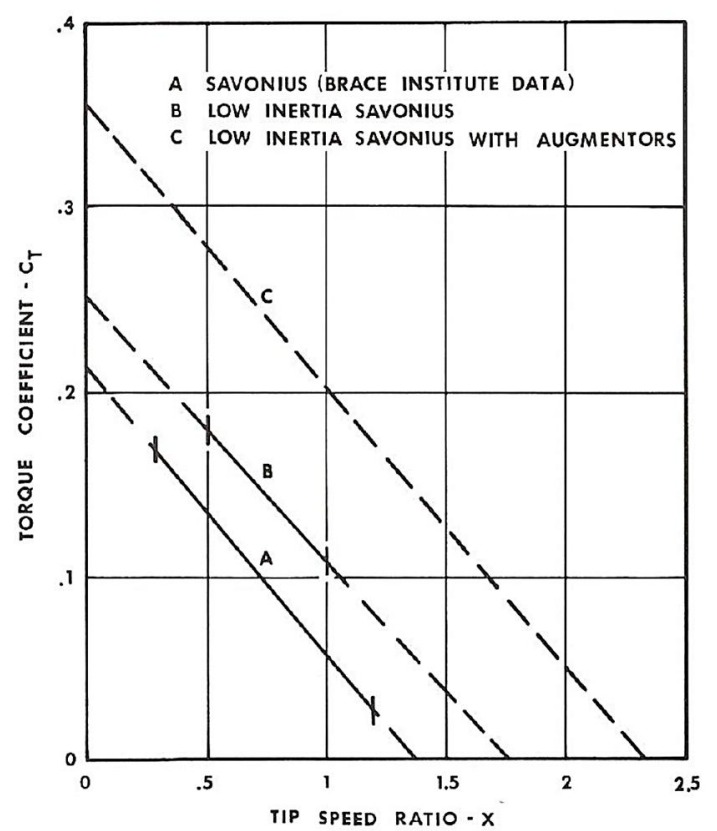

Fig. 4. Torque Coefficient and Tip speed ratio relationship of Savonius rotor models [2].

The slope (line C) of low inertia Savonius rotor with augmenters was chosen. From this information, the equation of torque coefficient $C t$ of the rotor could be derived by applying equation of a straight line with negative gradient. From the graph of Fig. 4, the straight line equation of slope $\mathrm{C}$ is deduced.

$C_{t}(\lambda)=-K X(\lambda)+B\left(C_{t}\right)$

where $B$ is the intercept along $C t$ axis, $x$ is tip speed ratio parameter along $(\mathrm{x})$ axis and $K$ is the gradient of the graph.

\section{B. IEHEC Motor}

IEHEC motor is a permanent magnet synchronous electrical motor, consisting of integrated toothed-coil permanent magnet and axial piston hydraulic pump directly driven by the same shaft, this allows for operation in high pressure application. Performance evaluation carried out indicates an efficiency of about $95 \%$ at $150 \mathrm{Nm}$ and $1000 \mathrm{rpm}$ [24]. The control of the IEHEC is an electrical frequency converter for fast response in dynamic application and can be used both in pumping and motoring modes [25]. With its high efficiency and fast dynamic response, IEHEC motor's application is wide ranging and very suitable for integrated operations [24]. The fast dynamic response of this system stems from use of powerful electrical drive technology [26]. Displayed in Fig. 5 are sectional and side views of the IEHEC motor respectively. Table 1 outlines the system specifications.
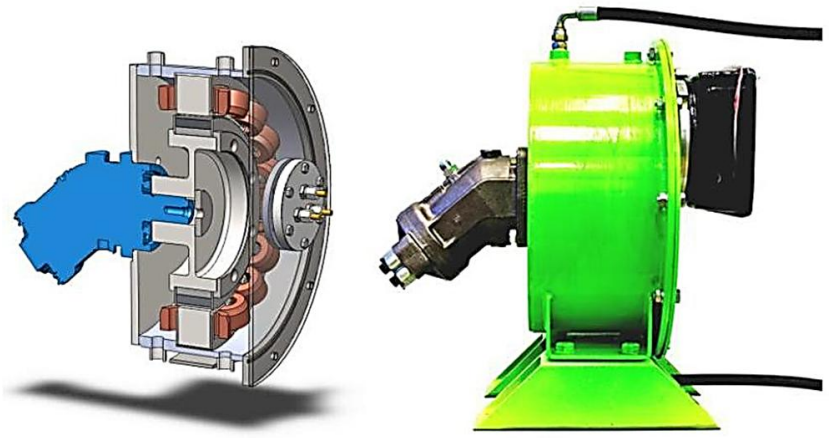

Fig. 5. Sectional and side views of an IEHEC Motor [24].

TABLE 1. IEHEC MOTOR SPECIFICATION [24].

\begin{tabular}{|l|c|}
\hline \multicolumn{1}{|c|}{ Parameter } & Value \\
\hline Length & $398 \mathrm{~mm}$ \\
\hline Weight (EM + HM) & $110 \mathrm{~kg}(92 \mathrm{~kg}+18 \mathrm{~kg})$ \\
\hline Nominal power & $26 \mathrm{~kW}$ \\
\hline Flow rate & Up to $1801 / \mathrm{min}$ \\
\hline Pressure & Up to $400 \mathrm{bar}$ \\
\hline Rated voltage & $400 \mathrm{~V}$ \\
\hline Nominal current & $44 \mathrm{~A}$ \\
\hline Coolant flow & $41 / \mathrm{min} @ 70^{\circ} \mathrm{C}$ \\
\hline Nominal speed & $1500 \mathrm{RPM}$ \\
\hline Supply frequency at nominal speed & $200 \mathrm{~Hz}$ \\
\hline Measured torque density at nominal point & $4.4 \mathrm{Nm} / \mathrm{Kg}$ \\
\hline
\end{tabular}

In the study; the IEHEC motor mimicking the Savonius turbine is controlled with the parameters of the wind turbine. Speed signal from simulation interacts with the frequency converter which in turn defines the speed of the motor. Using Newton's second law for rotation, angular acceleration of wind turbine is defined [27].

$\ddot{\theta}=\frac{M_{w t}+M_{p}}{J}$

where $J$ is the rotor Inertia. By integrating the angular acceleration, the angular velocity is achieved.

$\int \theta \stackrel{\ddot{=}}{\omega} \omega$

Inertia of the rotor is defined by:

$J=0.5 m r^{2}$ 
where $m$ is the mass of rotor. The pump input torque $\left(M_{p}\right)$ [28] is given by

$M_{p}=\frac{V_{k} \Delta p_{p}}{2 \pi}$

where $p$ is the pump pressure and, $V_{k}$ is the fixed volume displacement of the integrated pump of the IEHEC motor rated at $63 \mathrm{~cm} 3 / \mathrm{rev}$. It should be noted that the pump input torque $M_{p}$ is a resistance torque, hence opposes the rotational speed of the turbine. Figure 6 presents a typical Savonius rotor design where $D$ and $D_{0}$ are the internal and external diameters of the blades respectively, $\mathrm{d}$ is the radius and $c$ represents the distance between the ends of the blades at the point of connection to the central shaft. It should be noted that the mass used in simulation models is $362 \mathrm{~kg}$.
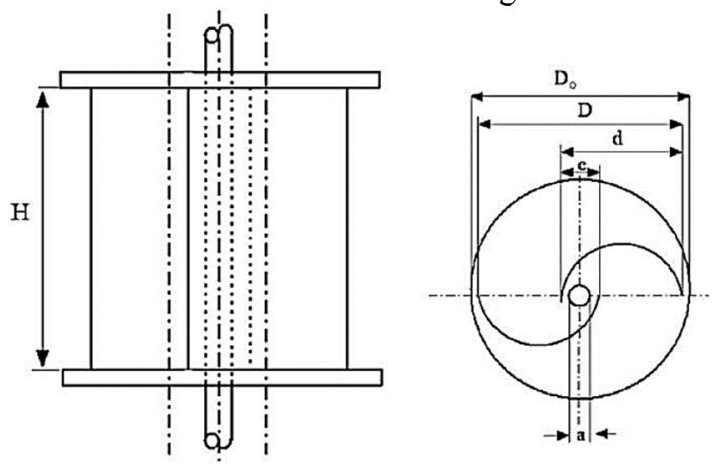

Fig. 6. Illustration of a single-stage Savonius rotor [29].

\section{Valves}

Valve is one of the principal components used in hydraulic systems. Applications range from flow control to pressure control applications. In the system set-up, both valve types were used. These include a throttle valve and a pressure relief valve. For simplicity, the focus of this Chapter will be on the throttle valve. A brief introduction of the pressure relief valve will be highlighted.

\section{Pressure relief valve}

As a matter of safety, pressure relief valves are required in any hydraulic system where the source pressure could exceed the pressure calibration of components downstream of the hydraulic circuit. Otherwise in a situation where a specified pressure level should not be exceeded. Where fixed displacement hydraulic pump is used as is the case in this set-up, it is recommended the use of pressure relief valve alongside [30]. In these cases, the pressure relief valve setpoint is set to open and bypass the excess pressure to the tank to avoid overload. The set-point at which the valve spring force equals the pressure force and valve starts to open is referred to as the cracking pressure [31]. Hence:

$p_{c}=\frac{F_{S 0} \pm F_{C}}{A_{v}}$

where $p_{C}$ is the cracking pressure, $F_{s}$ is spring force preload $=\left(k_{s} \times x_{0}\right), F_{c}$ is coulomb friction force and $A_{v}$ is poppet area normal to pressure. A typical direct acting pressure relief valve is presented in the Fig. 7. To maintain a constant flow rate in the system, the calibrated valve pressure set point of 200 bars must not be exceeded. Hence operation within this pressure limit ensures that the system is safe.

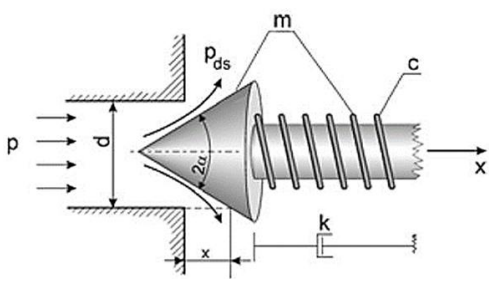

Fig. 7. A direct acting pressure relief valve, where pds is discharge port pressure, $\mathrm{k}$ is viscous force coefficient, $\mathrm{x}$ is poppet displacement, $\mathrm{m}$ is mass of the moving parts, $d$ is diameter of orifice and $c$ is spring stiffness [32].

\section{E. Hydraulic throttle orifice}

One of the vital components of the system set-up, responsible for flow regulation, and subsequently, torque vis-à-vis, pressure build-up and thermal power generation is the flow control pin valve. This valve uses a throttle mechanism through which fluid flow is constricted by adjusting the valve stem. This results in pressure differential across the valve. Application of high velocity short throat orifice when working with high pressure fluids aimed at achieving high pressure drop is common practice. This serves to limit the risk of cavitation, erosion to the valve components and damaging shock wave in the system when working with fluid susceptible to flash [33].

Though the focus of this study is not to seek to improve the design performance of the throttle valve, it is worth outlining that high velocity flow of fluid through the orifice is the bane of controlling valve operation. Hence the operating characteristics, operating limit and operation life of the valve should be considered. The pin valve used in the set-up is a DV Series flow control valve. DV-16 is an inline mounting valve.

\section{F. Throttle Valve Mechanism}

The valve in question is a manually operated pin valve. By turning the control knob of the valve, hydraulic flow could be regulated. Starting from closed position, the valve is opened by turning the valve knob anti-clockwise and closed by turning in clockwise direction. Calibration on the on the knob allows for repeatability of the process. Among parameters of the valve to be measured are the semi-empirical flow coefficient $\left(K_{v}\right)$ detailing flow characteristics with each number of turns of the valve knob and the orifice diameter of the valve. Using orifice volume flow equation [35], the orifice area $\left(A_{O}\right)$ could be calculated, thus:

$A_{o}=\frac{Q}{C_{d} \sqrt{\left(\frac{2}{\rho_{\text {oil }}} \Delta p\right)}}$

where $Q$ is volume flow across valve (measured using flow sensor), is pressure difference across valve, $C_{d}$ is nondimensional parameter; the orifice discharge coefficient approximately 0.61 for circular valve orifice geometry, and $P_{\text {oil }}$ is the oil density $\left[\mathrm{kg} / \mathrm{m}^{3}\right]$. Similarly, the semi-empirical flow coefficient of the valve $\left(K_{v}\right)$ depicting flow and pressure drop relationship could be evaluated [36].

$K_{v}=Q \sqrt{\left(\frac{\rho_{o i l}}{\Delta p}\right)}$

Thermal power $(P k)$ is generated as fluid passes through the constricted valve. The power generated is a function of fluid flow rate and pressure drop across the valve [35]. 
$P_{k}=Q \Delta p$

Figure 8 demonstrates the behavior of flow through the throttle orifice, where $P_{1}$ is inlet pressure, $P_{2}$ is outlet pressure, $v_{1}$ is inlet fluid velocity, $v_{2}$ is fluid velocity across the orifice and $d$ is orifice diameter. At low velocity, flow is laminar and turbulent with increasing velocity.

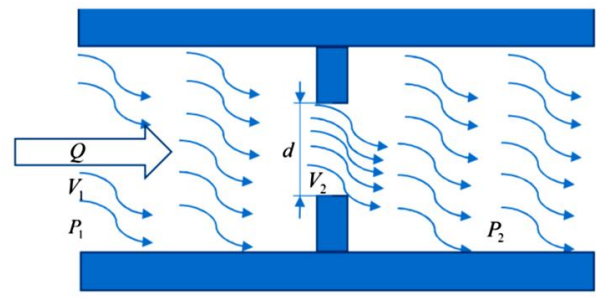

Fig. 8. Cross-section of flow through a throttle orifice.

\section{G. Cooler}

Heat exchangers (coolers) perform the function of temperature exchange between two fluids without them coming into contact. The use to which they are put, either to collect or dissipate heat from a body depends on the need of application. There exist various kinds of heat exchangers in commercial application. In this experiment as has been outlined earlier, the heat exchanger is to dissipate the heat generated in the hydraulic fluid and used for house heating. An oil to air heat exchanger operating on the mechanism of force convective heat transfer was used. The off/on controlled fan of heat exchanger is equipped with a 0.25 $\mathrm{kW}$ rated motor operating at $50 \mathrm{~Hz}$ (3000 RPM) maximum fan rotor speed. By Newton's law of cooling, the radiative power $P_{r}$ of the cooler can be derived [39].

$P_{r}=h_{t} A_{r}\left(T_{f}-T_{a}\right)$

where $h_{t}$ is convective heat-transfer coefficient of the radiator $\left[\mathrm{W} / \mathrm{m}^{2}{ }^{\circ} \mathrm{C}\right], A_{r}$ is radiative area $\left[\mathrm{m}^{2}\right], T_{f}$ is final oil temperature $\left[{ }^{\circ} \mathrm{C}\right]$ corresponding to the radiator plate temperature and $T_{a}$ is the ambient air temperature $\left[{ }^{\circ} \mathrm{C}\right]$. However, theoretical approach is deemed more suitable to analyze the result of the cooling unit. Calculations is carried out using parameters of a known oil cooler to estimate the heat output of the system. This is due to unavailability of manufacturer's performance characteristic information of the cooler used in the set-up and thus, accurate results cannot be guaranteed. In addition, short experiment time and low oil temperature difference recorded in the pre-trial experiment makes the use of the cooler barely relevant. The amount of heat generated in the fluid is attributed to the volume of oil used and short time span of the experiment cycle. The heat load $(P h)$ of the system over an operating time period is expected to tally that of the turbine power as no work is done by the hydraulic fluid in the system [11]. This is derived thus:

$P_{h}=\frac{V\left(T_{f}-T_{\infty}\right)}{60 \Delta t}$

where $V$ is the tank volume $\left[\mathrm{m}^{3}\right], t<t$ time period over temperature measure [s], and $T_{\infty}$ is ambient oil temperature $\left[{ }^{\circ} \mathrm{C}\right]$. Using this approach, it is assumed that the final oil temperature $\left(T_{f}\right)$ corresponds to the radiator plate temperature at the elapse of experiment time. To choose a suitable radiator, the power loss $P_{v}$ is evaluated using the equation as given [40].
$P_{v}=\frac{V \rho_{\text {oil }} C_{\text {voil }}\left(T_{f}-T_{\infty}\right)}{60 \Delta t}$

Where $P_{\text {oil }}$ is density of the oil; for mineral oil: $915 \mathrm{~kg} / \mathrm{m}^{3}$, $C_{\text {voil }}$ is specific heat capacity of oil; for mineral oil 1.88 $\mathrm{kJ} / \mathrm{kg}^{\circ} \mathrm{C}$. For a given air temperature $T 1\left[{ }^{\circ} \mathrm{C}\right]$ and a desired oil temperature of $T 2\left[{ }^{\circ} \mathrm{C}\right]$, the specific cooling capacity $P_{S C}$ $\left[\mathrm{kW} /{ }^{\circ} \mathrm{C}\right]$ of the cooler could be calculated by [40]

$P_{S C}=\frac{P_{v}}{\left(T_{2}-T_{1}\right)}$

\section{H. Hydraulic Oil}

Hydraulic fluid is a vital element of any hydraulic operating system. Hydraulic fluids have found application in forestry, marine and more frequent in mobile equipment for power transmission, wear protection, cooling and heat transfer. One of the underlying hydraulic fluids' properties that determine its suitability is its viscosity- temperature behavior. The relationship is inversely proportional with increasing or decreasing fluid temperature [41]. High viscosity index ensures wide temperature operating range of the fluid. Other properties required of good hydraulic fluids are low compressibility, low foaming tendency, high oxidation stability over a time period, tribological compatibility with materials, environmental impact and many others $[42,43]$.

Leakages and pressure loss in hydraulic components are common problems of pressurized systems. With hydraulic oil, these problems are exacerbated by cavitation and oil viscosity [44]. With about $9 \%$ air content in solution of mineral based hydraulic oil under atmospheric condition, cavitation in the fluid affects the dynamic power transmissibility of the fluid [44] and hampers the performance of the components in the system. In use in the experiment is mineral based hydraulic oil HVLP 46 was used for its durability, availability in various viscosity grades, toxicogical behavior, hydrolytic stability and good thermal property in power transmission and heat transfer application. It is recommended to operate at permitted viscosity drop of $15 \%$, at temperature reaching $100^{\circ} \mathrm{C}$ [41]. Presented in Table 3 and Fig. 9 are the properties and viscosity - temperature relation of HVLP 46 hydraulic oil. A high viscosity index indicates a small change in viscosity with changes in temperature and low index means a large viscosity change with change in the oil temperature.

As is the case with any moving substance in contact with itself and other substance, friction is ever present. In flowing hydraulic fluid, friction contribute to the temperature rise in the system. More so, compression and expansion of the fluid as it passes through the valve increases the intermolecular activity present which results in stresses and tearing of molecular chains to add more heat to the fluid [11].

TABLE 3. HydRAULIC OIL HVLP 46 PROPERTIES [43].

\begin{tabular}{|l|c|}
\hline \multicolumn{2}{|c|}{ Ultramax HVLP 46 } \\
\hline Colour & Yellow \\
\hline Viscosity, mm2/s @ $100{ }^{\circ} \mathrm{C}$, ASTM D-445 & 8,1 \\
\hline Viscosity, mm2/s @ $40{ }^{\circ} \mathrm{C}, \mathrm{ASTM}$ D-445 & 46 \\
\hline Viscosity Index, ASTM D-2270 & 148 \\
\hline TAN; mg KOH/g, ASTM D-664 & 0,6 \\
\hline Pour Point, ${ }^{\circ} \mathrm{C}, \mathrm{ASTM}$ D-5950 & -45 \\
\hline Specific Gravity @ $15.6{ }^{\circ} \mathrm{C}, \mathrm{ASTM}$ D-4052 & 0,858 \\
\hline Flash Point, COC, ${ }^{\circ} \mathrm{C}, \mathrm{ASTM}^{\mathrm{A}} \mathrm{D}-92$ & 225 \\
\hline
\end{tabular}




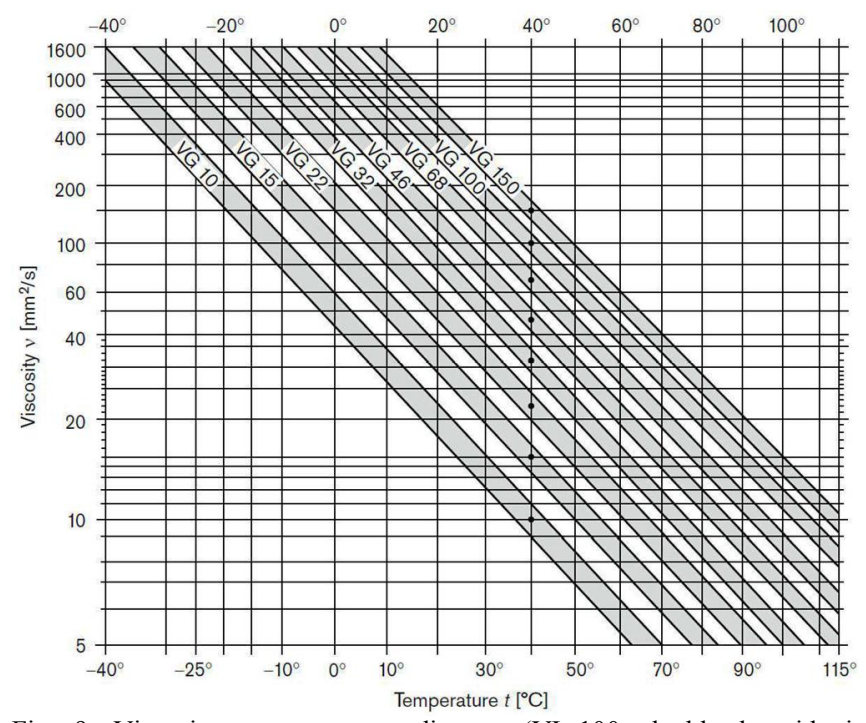

Fig. 9. Viscosity - temperature diagram (VI 100, double logarithmic representation) [41].

\section{Oil reservoir}

The oil reservoir in use is a steel enclosed tank measuring up to 300 liters in capacity. The primary function of the tank is storage and recirculation of the hydraulic fluid. Connected to the tank are the suction line to the pump and the return line as represented in Fig. 10.

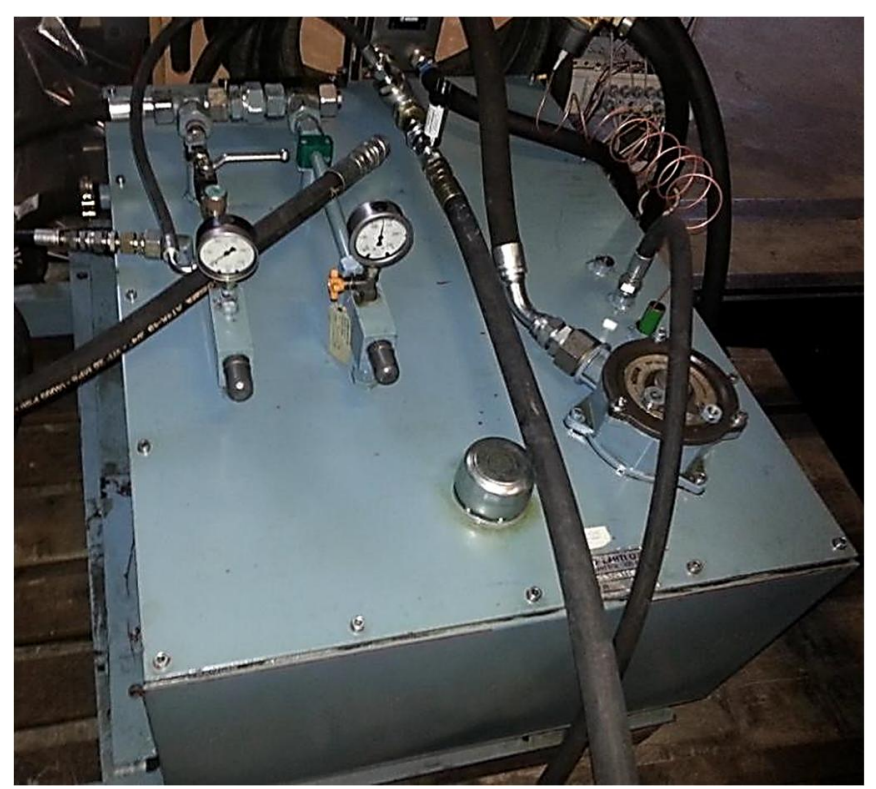

Fig. 10. Hydraulic oil tank.

Other than hydraulic fluid storage, the tank also serves as a heat storing component. The undissipated heat in the return oil infinitesimally accumulates thereby raising the temperature of the fluid in the tank. Owing to the material of the storage, energy is loss through conduction. This energy could be made useful if tapped and used for floor eating. This implies close proximity of the storage tank to the target usage area. The phenomenon of heat accumulation in the tank is described by tank oil temperature $T_{t}$ as given [1].

$T_{t}=\frac{P_{t}}{\rho_{\text {oil }} V C_{\text {voil }}}+T_{\infty}$

Similarly, the tank thermal energy $P_{t}$ (in the oil returning to the tank) could be calculated.
$P_{t}=P_{k}-P_{r}$

\section{EXPERIMENTAL DESIGN}

In this Chapter the experimental simulation, system set-up and system control is described. The virtually simulated model of system from previous study in relation to the laboratory experimental process is briefly explained. The interaction between the hardware components, signal processing and integration of hardware of real time interface (dSPACE) with Matlab/Simulink software in the experiment is outlined.

\section{A. Virtual simulation model}

Encompassed in the virtual simulation model are equations representing the different components that make up the circuit. The rotor is the power source for driving the hydraulic pump. Other parts modelled include the throttle valve, pressure relief valve, oil to air heat exchanger and hydraulic fluid storage tank. The fluid power circuit was modelled and simulated in Simulink using semi-empirical modelling method.

In the earlier study of the system, two different torque coefficients $\left(C_{t}\right)$ were applied in the virtually simulated system model to test for optimum orifice diameter at which power output is maximized. It was determined from calculation and test simulations that the optimum orifice diameter of the model is a function of the turbine's tip speed ratio which depends on the wind speed and load on the turbine (pump torque). This relationship is given in Fig. 11.

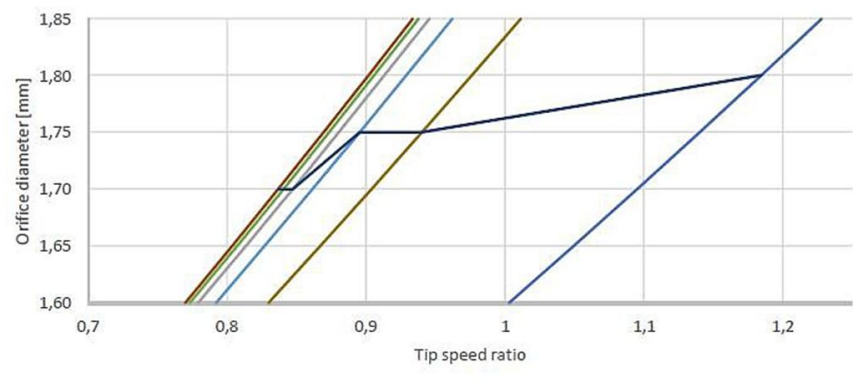

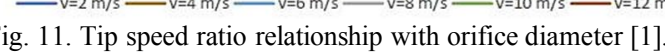

From the outcome of this test, the turbine was found to operate optimally at torque coefficient of 0.35 . [1] This claim is the focus for verification of the modelled turbine's optimum torque coefficient parameter. To harness optimum power from the wind, the throttle orifice has to be adjusted to achieve an optimum tip speed ratio of the turbine.

\section{B. Hardware-in-the-loop simulation}

The experiment is designed by method of HIL simulation. The virtual turbine simulation model is used in tandem with the experimental system hardware set-up. A sample wind profile of constant wind speeds $(2 \mathrm{~m} / \mathrm{s}$ to $12 \mathrm{~m} / \mathrm{s})$ over a 30 minutes' time period was designed to run in the simulation. System pressure input parameter was measured directly from the system responses using sensor. The pressure variable determines the pump output torque. Imbedded equations calculate turbine's tip speed ratio and torque coefficient. These parameters control the motor's speed. 


\section{Experimentation}

The experiment made use of commercially available hardware for system set-up. The rotational speed output signal of the virtual Savonius turbine model controls the speed of the IEHEC motor which drives the pump. Simulation was set to infinite time and stopped at the elapse of wind speed data sample time. Connected to the integrated motor unit is a frequency converter which varies the frequency of the motor with change in the rotational speed of the turbine model. This variation is as a result of change in the wind speed. The dSPACE hardware interacts and processes input sensor signals in the system set-up in real time.

The experiment is carried out by controlling the motor with the designed turbine model while regulating the valve orifice. The valve is increasingly opened by turning the valve knob anti- clockwise till full opening. The valve knob is calibrated between 0 to 9 numbers of repeatable turns. The valve knob for the experiment were set to 2, 3, 4, 5, 6 and 7 number of turns and their corresponding orifice diameters were measured and documented in the result chapters. Having established the relationship between optimum throttle orifice with respect torque coefficient and wind speed, the Savonius turbine model of slope $\mathrm{C}$ in Fig. 4 and Eq. 8 depicting the torque coefficient of the turbine was applied in the turbine torque model.

Preliminary tests were carried out to verify the pressure limit of the system. This is to ascertain that the system does not exceed the 200 bar pressure limit. To this effect, the system could be said to maintain a constant volume flow at any given time throughout the system. Displayed in Fig. 12 is an assembly of the hardware components of the system.

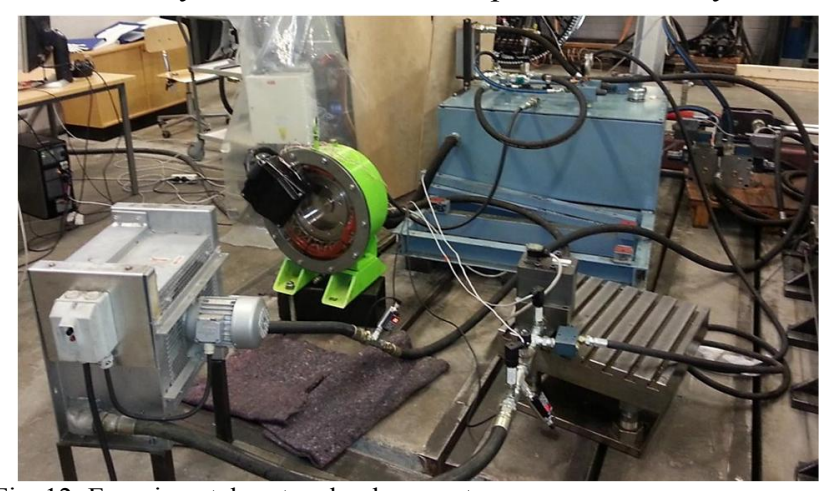

Fig. 12. Experimental system hardware set-up.

\section{RESULTS AND DISCUSSION}

This Chapter presents the results of the laboratory experiments. The virtual simulation and test bench results from previous study [1] are presented as well. Analysis and comparison of results is carried out to verify prior inferences. Similarly, the throttle valve characteristic behavior of the valve manufacturer is compared with the simulated characteristics. Emphasis is laid on the valve optimum orifice diameter in relation to tip speed ratio, torque coefficient and thermal power output.

\section{A. Virtual simulation result}

The objective of presenting the result of the virtual simulation is to investigate correlation with the experimental results. As mentioned earlier, variations exist in the parameters used in these two models. One variation is the wind speed data used in the virtual simulation as recorded by the Finnish meteorological institute (See Fig. 13)

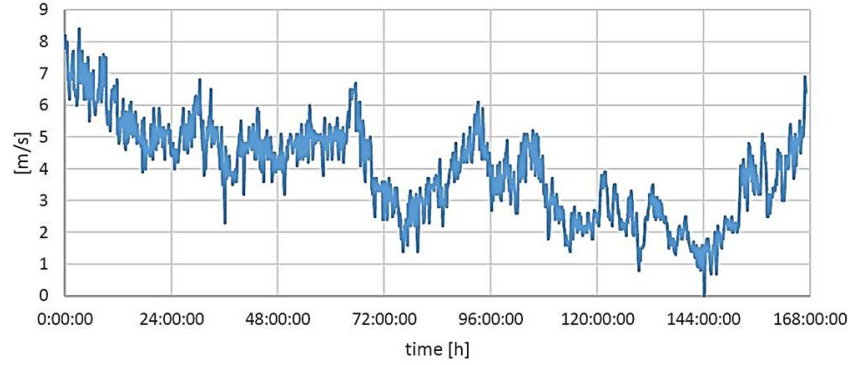

Fig. 13. Wind speed data applied in virtual system simulation [1].

The optimum orifice diameter used in the models varied as well. These parameters (wind data and orifice diameter) used in the experiment is sampled in the virtual simulation as well. Average of the wind speed data was used to calculate the optimal orifice diameter used in the test bench and as well to compute the output results of the virtual system recorded in Table 3 [1]. Two torque coefficients were simulated in the virtual simulation. The result of the simulation claims optimum torque coefficient $C t=0.35$, having higher power output. This torque coefficient parameter is subjected to scrutiny in the experimental Savonius turbine model.

TABLE 3. CALCULATED POWER VALUES FROM THE WIND DATA [1].

\begin{tabular}{|l|c|c|}
\hline Torque coefficient (Ct) & 0.25 & 0.35 \\
\hline Average wind speed [m/s] & \multicolumn{2}{|c|}{3.95} \\
\hline RMS of wind speed [m/s] & \multicolumn{2}{|c|}{4.44} \\
\hline Power of average wind speed [W] & 14.7 & 28.3 \\
\hline Power of RMS wind speed [W] & 21.0 & 40.5 \\
\hline Simulated power of rotor [W] & 22.8 & 41.6 \\
\hline Total power produced by average wind speed [W] & 2453.3 & 4731.4 \\
\hline Total power produced by RMS of wind speed [W] & 3505.8 & 6761.3 \\
\hline Total simulated power [W] & 3803.8 & 6946.7 \\
\hline Total power production per annum (RMS) [kW/a] & 183.9 & 354.7 \\
\hline Total simulated power production per annum [kW/a] & 19.5 & 364.4 \\
\hline
\end{tabular}

\section{B. Virtual system optimum parameters evaluation}

The supposed optimal orifice diameter of $1.85 \mathrm{~mm}$ was applied in the virtual rotor simulation at optimum torque coefficient $C_{t}=0.35$ under constant wind speed $v=10 \mathrm{~m} / \mathrm{s}$ to verify the output value presented in Fig. 14.

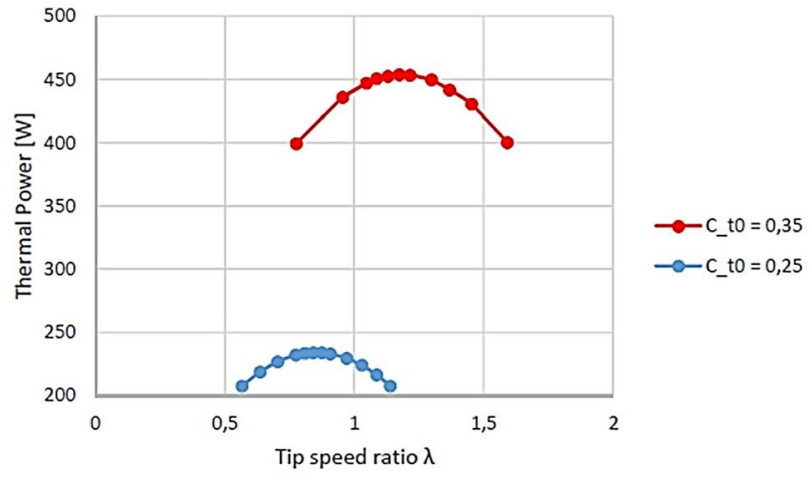

Fig. 14. Tip speed ratio - power relationship of Virtual turbine model [1].

An assessment of the presented result (Fig. 14) was carried out using constant wind speed over time. The parameters of the virtually simulated system (optimum orifice diameter of the virtually simulated throttle orifice simulation at wind speed of $10 \mathrm{~m} / \mathrm{s}$ and torque coefficient of 0.35 ) inputted gave rise to the result displayed in Fig. 15. 
From this result, the claimed optimum tip speed ratio of 1.17 in previous study [1] was not achieved. Similarly, the torque coefficient of 0.35 was not achieved. Figure 16 shows that at cut-in wind speed of the turbine, the torque coefficient started to decline from initial value of 0.35 . Output power of the turbine is not optimal at this point.

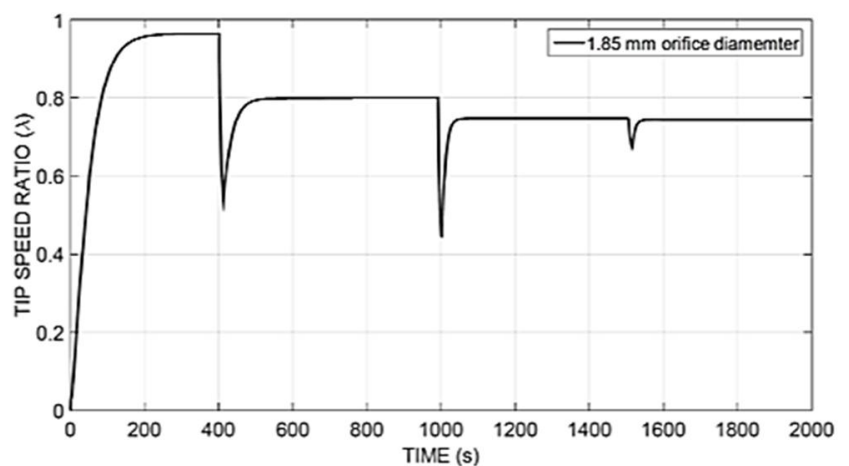

Fig. 15. Tip speed ratio of Virtual turbine model.

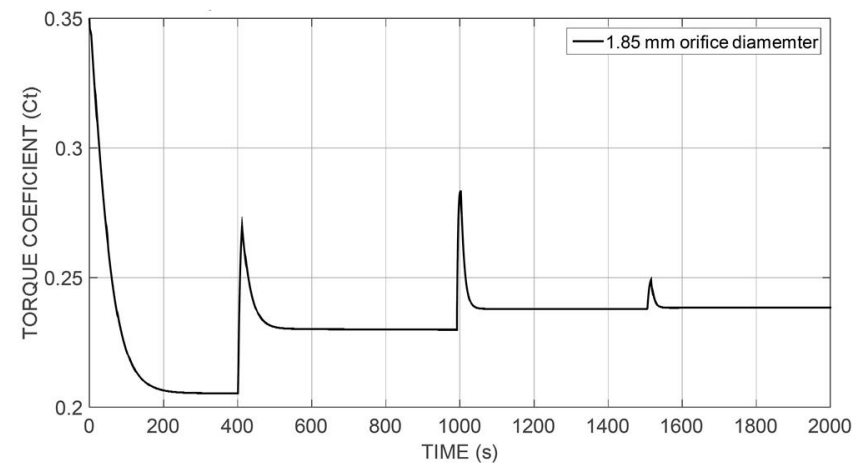

Fig. 16. Torque coefficient of Virtual turbine model.

\section{Test bench simulated result}

Test bench from previous research is similar to the experimental set-up with some modifications. It served the purpose of empirical research to examine the parametric effect of generated power and optimal tip speed ratio of the system using two different torque coefficient values of the turbine [1]. A constant wind speed of $10 \mathrm{~m} / \mathrm{s}$ was used in simulation. The optimum orifice diameters at the different torque coefficients were noted as well. Owing to the similarity in the two models (Test bench and laboratory experimental models), the results at the same operating conditions are more readily compared.

\section{Turbine power and tip speed ratio characteristics of test bench model}

By adjusting the throttle orifice in the test bench set-up, it was reported that optimal throttle orifice of $2.5 \mathrm{~mm}$ was reached for turbine simulation with torque coefficient of 0.35 . Similarly, the optimal tip speed ratio which is wind speed dependent is achieved [1]. The Result of the study as presented in Fig. 17 shows an optimal tip speed ratio of 1.17 was reached for rotor of torque coefficient $C_{t}=0.35$ and 0.84 for rotor of torque coefficient $C_{t}=0.25$. However, going by graph $\mathrm{C}$ of Fig. 4 depicting torque coefficient and tip speed ratio relationship of the Savonius turbine model used, the corresponding torque coefficient at tipspeed ratio of 1.17 is below 0.2 . To investigate further, parameters of the test bench is configured in the virtual system simulation and result evaluated.

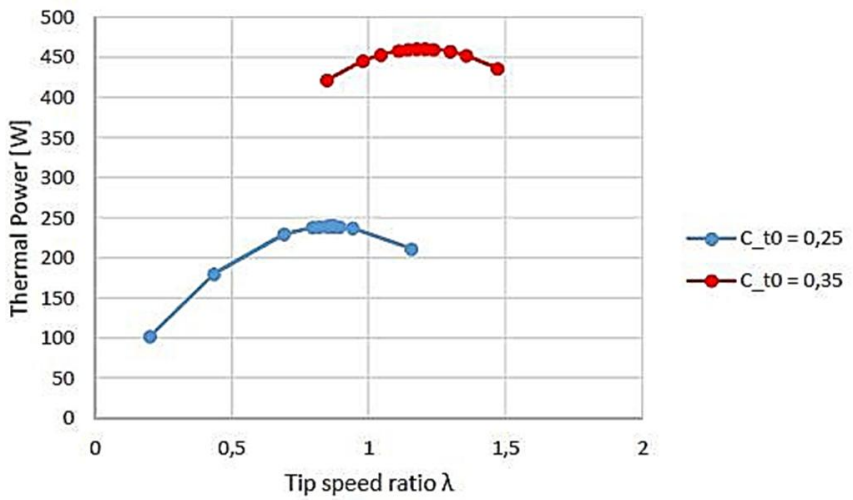

Fig. 17. Effect of optimal tip speed ratio for different torque coefficient on power output [1].

\section{E. Test bench optimum parameters evaluation}

Using constant wind speed profile shown in Fig. 18 and test bench parameters (optimum valve orifice diameter of 2.5 $\mathrm{mm}$ and torque coefficient $C_{t}=0.35$ ), the tip speed ratio and corresponding torque coefficient were presented in Fig. 18 and Fig. 19 respectively. Emphasis is laid on the response of the system in wind speed range of $10-12 \mathrm{~m} / \mathrm{s}$. Tip speed ratio of 1.19 was recorded.

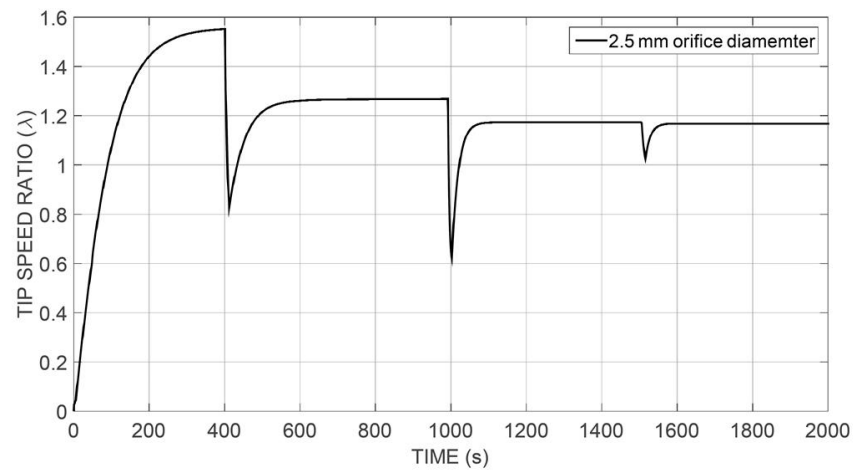

Fig. 18. Tip speed ratio evaluation using test bench parameters.

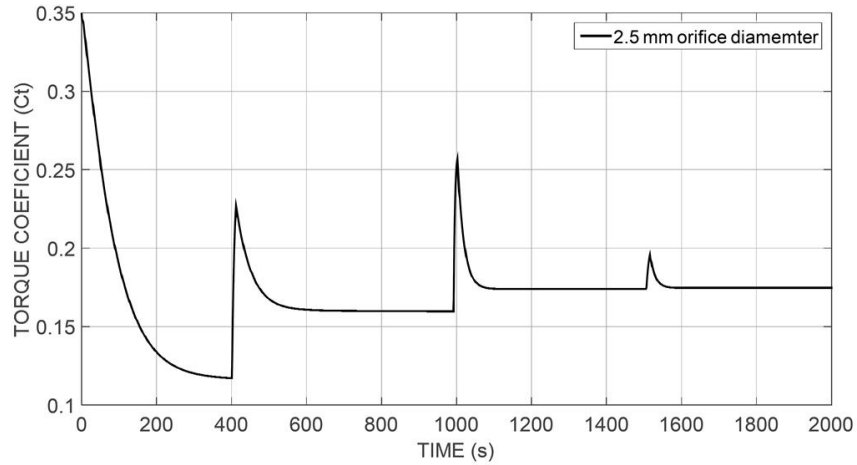

Fig. 19. Torque coefficient evaluation using test bench parameters.

This is close to the claimed optimum value of 1.17 . Similarly, the corresponding torque coefficient is below 0.2 . With these two results, it can clearly be said that the torque coefficient applied in the virtual design is not optimum at 0.35 . It is evident that torque increases with increasing wind speed. The fast change in turbine torque coefficient is as a result of pump load on the turbine. Hence the turbine output torque and pump input torque equalizes with time. This result is compared with the experimental simulation. 


\section{F. Experimental results}

The results of the experiment are tabulated in the following Chapters. The Wind speed data used and subsequently turbine speed is presented in Fig. 20 and Fig. 21 respectively.

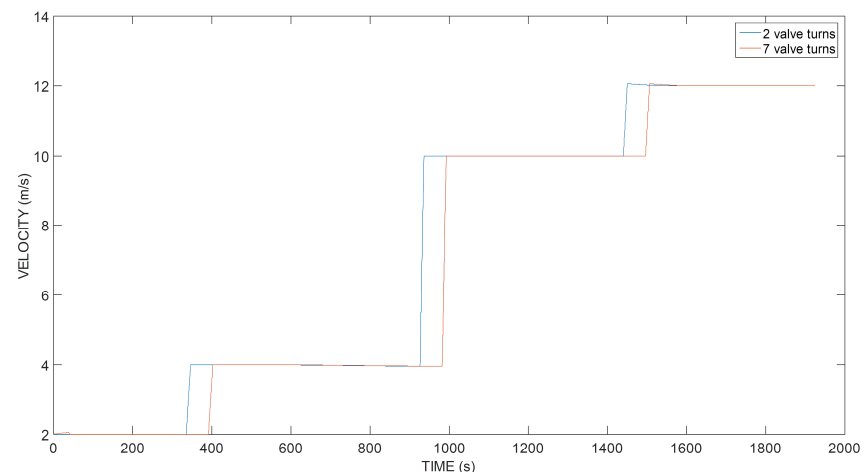

Fig. 20. Wind speed profile.

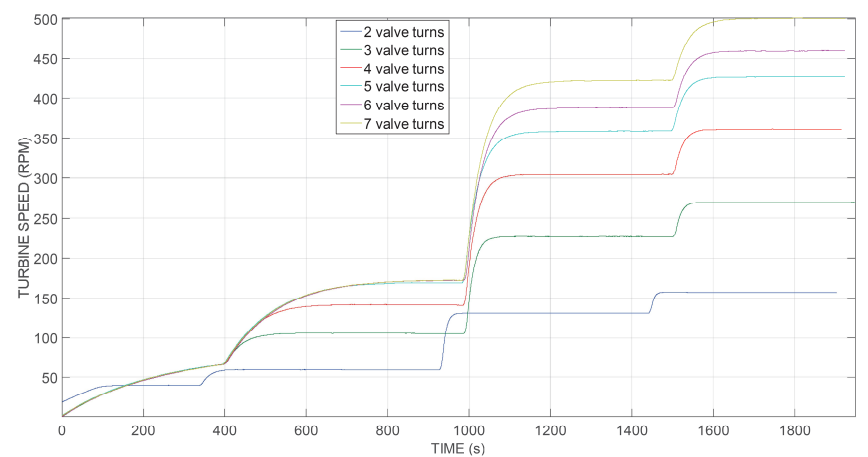

Figure 21. Rotational speed of turbine.

The deviation noticed in the wind speed at 2 valve turns is as a result of time off-set during data recording. Same wind speed profile was used throughout the experiment. Only the extreme valve setting (2 and 7 turns) results were represented due to the similarity of results at different orifice setting. This off-set is also noticed in some other results such as the torque coefficient, wind and system power outputs.

The turbine was monitored to ensure that its operating speed is within the rated limit of the IEHEC motor of 1500 RPM. Upper speed limit of the experimental turbine was set to 1400 RPM. Other measures taken to ensure safety includes an emergency switch to halt operation. Unlike conventional Savonius turbine which rotates in either direction of the wind force, the experimental turbine model is subject to one directional rotation due to open-loop hydraulic circuit. The rotation of IEHEC motor was permitted only to other direction Maximum recorded speed of the turbine at 7 opening turns of the valve knob stands approximately 500 RPM.

\section{G. Experimental turbine torque coefficient and tip speed ratio characteristics}

The torque coefficient - tip speed ratio parameter of the low inertia Savonius with augmenters (slope C) of Fig. 4 was adopted to achieve power output of commercially available wind turbine. This relationship is used to verify the adherence of the experimental turbine to the torque coefficient - tip speed ratio relationship. The similarity in the slope of the two graphs (Fig. 4 and Fig. 22) approximating to a value of 0.15 is calculated. From the maximum recoded turbine output power in the experiment, optimum tip speed ratio (see Fig. 23) is interpolated and found to be 1.2 corresponding to a torque coefficient of 0.175 . Note that only the extreme valve setting ( 2 and 7 turns) results were represented due to the similarity of results at different orifice setting.

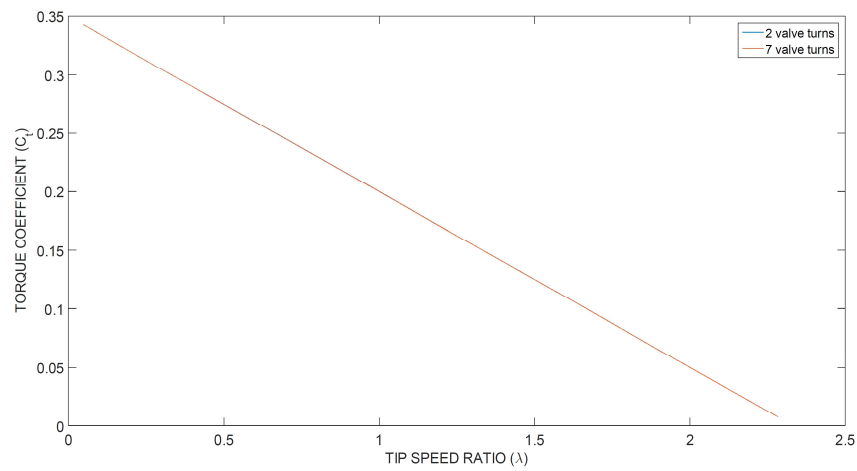

Fig. 22. Torque Coefficient vs tip speed ratio for IEHEC rotor.

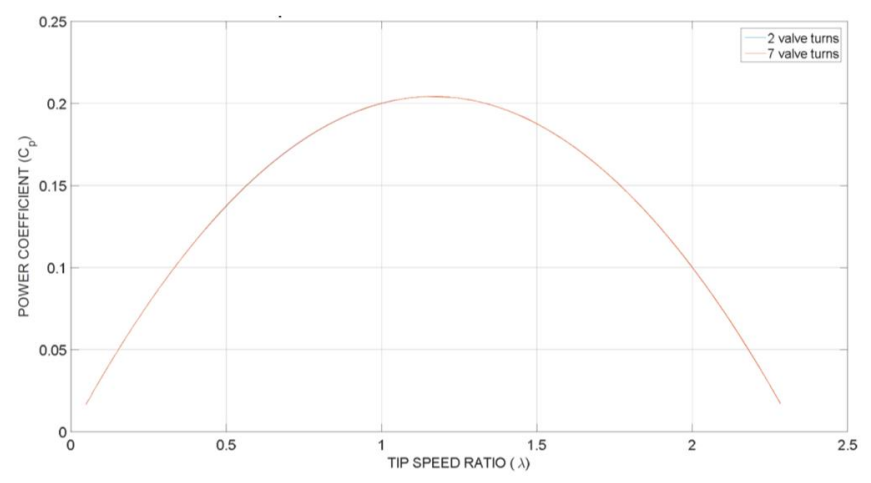

Fig. 23. Power coefficient - Tip speed ratio relationship of EIHEC turbine.

\section{H. Wind Power}

Change in wind power is as a result of change in wind speed and is independent of the turbine performance. Hence at maximum wind speed of $12 \mathrm{~m} / \mathrm{s}$, the power obtainable is approximately kW as shown in Fig. 24.

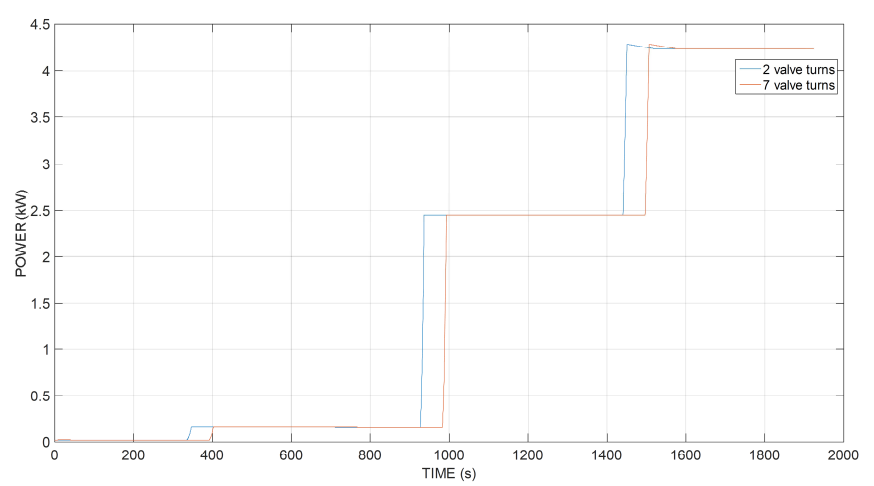

Fig. 24. Wind power.

As earlier noted, the deviation in result at different valve turns is consequent to off-set in data recording time. Only the extreme valve setting (2 and 7 turns) results were represented owing to similarity in results at other valve settings.

\section{Turbine power output}

As is earlier established, power output of the turbine is a function of the power coefficient which is dependent on the tip speed ratio of the rotor. 
Hence the valve orifice is adjusted so that the tip speed ratio traces the power curve of a practical turbine model. Figure 23 presents the power coefficient - tip speed ratio relationship of the experimental turbine, showing a concurrence in the power output of the turbine model in comparison to that presented in Fig.4. The optimum power coefficient of 0.205 was achieved corresponding to a tip speed ratio of about 1.2. The experimental turbine's tip speed ratio value is close to the tip speed ratio recorded in the test bench simulation (1.17) presented in Fig. 23 and the tip speed ratio in the virtual simulation (1.19) using test bench valve orifice parameter as shown in Fig. 8. Note that only results of extreme valve settings were presented following similarity in result at other valve settings.

\section{J. Torque Coefficients and Tip speed ratio}

Torque coefficient is defined as the ratio of power coefficient to the tip speed ratio. The optimum torque coefficient of 0.175 was achieved at 3 valve knob turns in wind speed range of $10-12 \mathrm{~m} / \mathrm{s}$. The optimum orifice of the test bench turbine model was calibrated in the experimental turbine. The output result is represented in Fig. 25 with the highlighted plot.

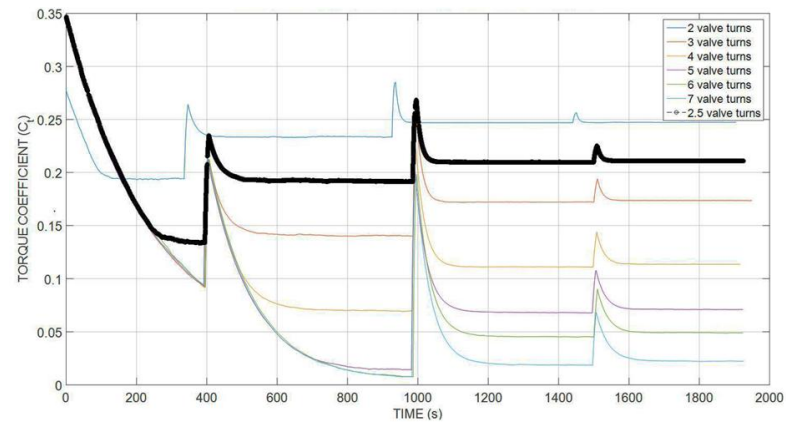

Fig. 25. Torque coefficient of simulated turbine.

The output torque coefficient observed is concurrent with the torque coefficient of the test bench presented in Fig. 13. However, the valve orifice at which the optimum parameters were achieved slightly differ in the two models; $2.5 \mathrm{~mm}(2.5$ valve turns) in the virtual model and $3 \mathrm{~mm}$ ( 3 valve turns) in the experimental model. Hence the difference in the torque coefficients.

Unlike in the virtual turbine model, the optimum orifice diameter of $1.85 \mathrm{~mm}$ could not be realistically calibrated in the experimental set-up. Hence the orifice setting of $2.0 \mathrm{~mm}$ is used in the experimental turbine to evaluate the virtual turbine model parameters. Figure 26 shows the tip speed ratio of the virtual turbine model ( 0.65 at 2 valve turns) in comparison to the tip speed ratio of the test bench turbine ( 0.95 at 2.5 valve turns).

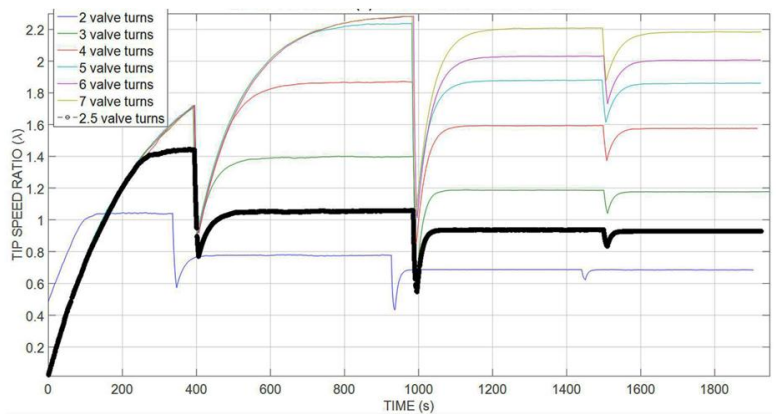

Fig. 26. Tip speed ratio of turbine at different valve turns.

\section{K. Turbine Power}

Figure 27 presents output power of the turbine at different valve orifice opening and wind speed.

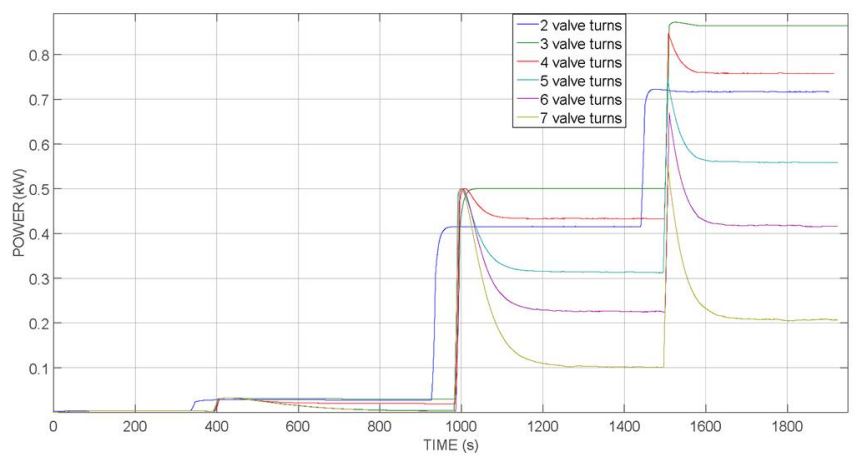

Fig. 27. Turbine power.

It could be observed from the graph an increasing power output with increase in wind speed. Considerable power output is achieved between wind speeds of $10-12 \mathrm{~m} / \mathrm{s}$. Maximum power output was achieved at 3 turns of the valve knob. Power outputs of $0.50 \mathrm{~kW}$ and $0.87 \mathrm{~kW}$ were recorded at $10 \mathrm{~m} / \mathrm{s}$ and $12 \mathrm{~m} / \mathrm{s}$ wind speed respectively. In latter pages, we will evaluate the corresponding valve orifice diameter in relation to the number of turns of the valve knob. Similarly, optimum power coefficient was recorded at 3 valve knob turns. Using the orifice area formulation, the valve orifice area was simulated. The diameter is calculated thus:

$D=\sqrt{\left(4 \times \frac{A_{0}}{\pi}\right)}$

The result of Fig. 28 shows simulated valve diameter corresponding to the number of valve knob turns.

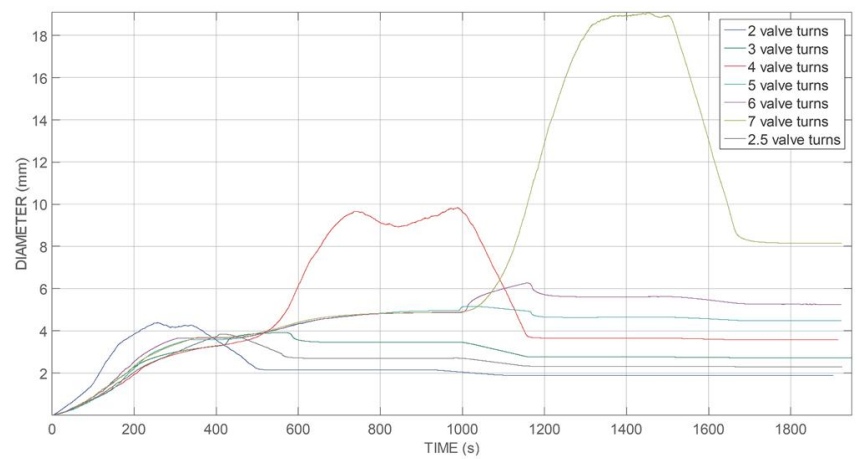

Fig. 28. Valve orifice diameter.

The optimum valve orifice at optimum power output at 3 valve knob turns (between $10-12 \mathrm{~m} / \mathrm{s}$ wind speed) is found to be $3 \mathrm{~mm}$. The spike in the signals were as a result of disturbances in the system with changing wind speed. The measured flow characteristic of the simulated valve closely follows the characteristic data provided by the manufacturer. This verifies the behavior of the valve in operation.

\section{Thermal Power}

Thermal power $\left(P_{k}\right)$ is calculated from flow and pressure drop across the valve using Eq. (16). The graph of Fig. 29 reveals the thermal power of the experimental system at different wind speed and valve orifices. 


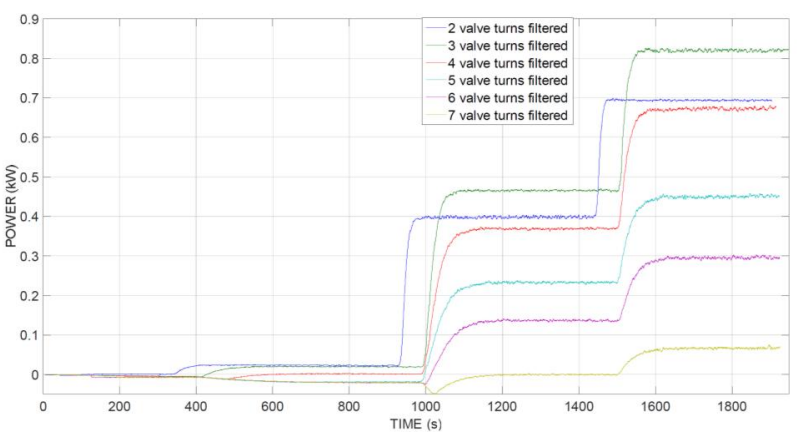

Fig. 29. Thermal Power.

Between wind speed of $2-4 \mathrm{~m} / \mathrm{s}$ and higher number of valve turns (4-7), an insignificant pressure difference is recorded and due to sensory limitations of the pressure transducer, negative pressure was recorded in some cases. Hence thermal power obtainable at wind speeds below 4 $\mathrm{m} / \mathrm{s}$ and orifice diameter above $3 \mathrm{~mm}$ is insignificant with this turbine parameter. Maximum thermal power output of approximately $0.82 \mathrm{~kW}$ at 3 number of valve knob turns and constant wind speed of $12 \mathrm{~m} / \mathrm{s}$ was achieved.

The power output of the system is dependent of the coefficient of performance of the system. The efficiency of the turbine in harnessing wind and the valve to generate heat were evaluated.

$C_{p k}=\frac{P_{k}}{P_{w t}}$

where $C_{p k}$ valve thermal power conversion efficiency. From calculation, these values at wind speed of $10 \mathrm{~m} / \mathrm{s}$ and 3 valve turns stand at 0.20 and 0.9 respectively. It is noticed that increasing wind speed resulted in increasing valve thermal power efficiency; an indication of high functional efficiency of chosen valve type. Figure 30 shows power obtainable from the wind speed profile in comparison to achieved turbine power at different valve knob turns.

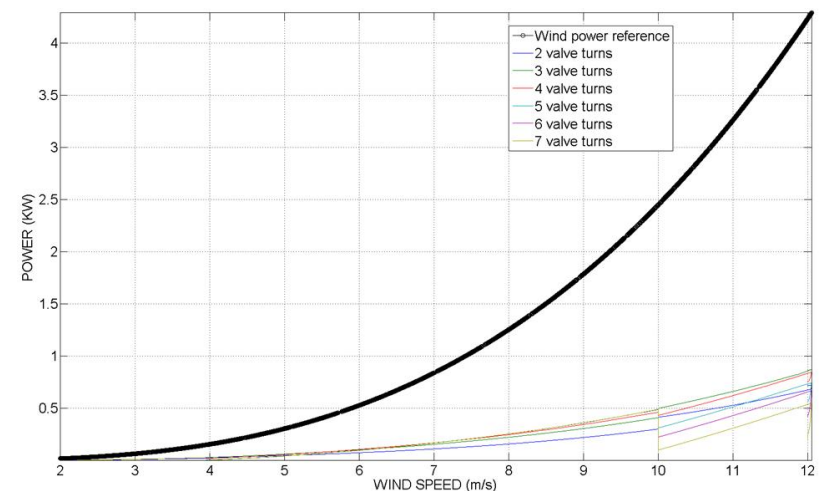

Fig. 30. Turbine power in relation to wind power.

The reference wind power is a calculation of power contained in the wind moving across the cross sectional area of the turbine blade without doing any work or obtainable at $100 \%$ power efficiency of turbine. Whereas the turbine power is calculated from power the turbine extracted from the wind at any given orifice diameter. Applying Eq. (5) and Eq. (24), the efficiency of turbine power and thermal power conversion of the system can be evaluated.

Consequent to fluid throttling is temperature rise in the fluid. Figure 31 maps the temperature change in the fluid measured at position after the throttle valve at different orifice set points.

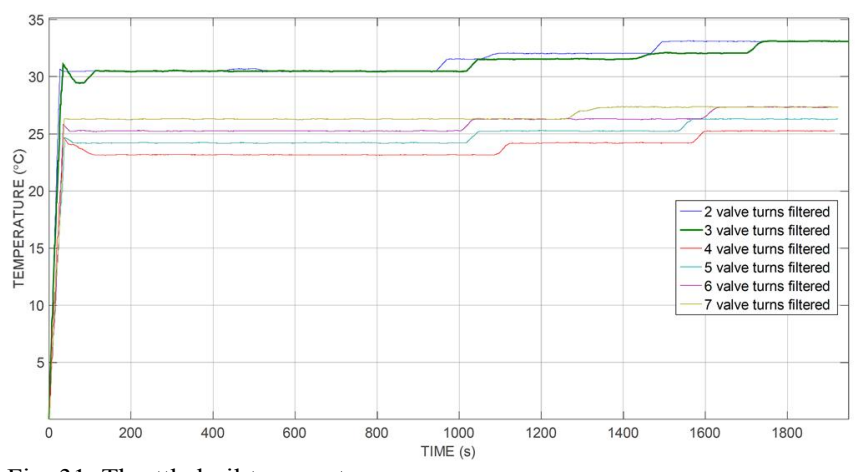

Fig. 31. Throttled oil temperature.

At time zero, the temperature transducer measures the ambient temperature of the fluid. The difference in temperature during each measurement cycle gives the heat input in the fluid. Thermodynamically, the temperature increase in the fluid resulting from pressure drop and hydraulic power required to move the mass flow across the valve orifice [35] is given by:

$T_{f}-T_{\infty}=\frac{\Delta p}{C_{\text {voil }} \rho_{\text {oil }}}$

At $3 \mathrm{~mm}$ orifice diameter setting, temperature difference of $4^{\circ} \mathrm{C}$ was achieved. Noticeably, higher temperature is achieved at higher pressure build-up which corresponds to higher wind speed. It should be noted that the higher temperature recorded at 2 and 3 valve turns were as a result of difference in the initial temperature of the oil at the start of the experiment.

By heat load from Eq. (18), and oil volume of 202.5 liters used in the experiment, heat load of approximately $0.8 \mathrm{~kW}$ was calculated. This validates the thermal power value of Fig. 29. Given an ambient air temperature of $26^{\circ} \mathrm{C}$ and throttled oil temperature of $34^{\circ} \mathrm{C}$, the specific cooling capacity of the cooler could be derived by applying Eq. (20). Also it is recommended to account for deficiency due to contamination with a $10 \%$ safety margin [40]. Hence $P_{s c}=0.1025(1.1)=$ $0,113 \mathrm{~kW} /{ }^{\circ} \mathrm{C}$. This power loss must be dissipated by the oil cooler.

\section{RECOMMENDATION}

It is understood that power output by the turbine is most efficient at an optimum tip speed ratio of the turbine. In this system, the tip speed ratio and consequently thermal power output of the turbine is influenced by the orifice diameter of the valve. This parameter controls the system torque, pressure build-up and hydraulic fluid flow rate, hence a critical parameter impacting the performance of the system.

In the current model of the system, the valve in use requires manual adjustment to achieve optimum setting. Given a fixed wind speed, the valve performance will be efficient, however the dynamic wind environment requires that the valve throttle mechanism be flexible and selfadjusting to achieve optimum condition. This could be achieved by use of hydraulic proportional valve with a feedback controller.

Proportional valve suitability stems from its lower cost and maintenance requirements compared to servo valve. Using optimum tip speed ratio parameter of the turbine in closedloop applications, the valve orifice could be adjusted with varying wind speed to operate at optimum set-point. A new 
semi-empirical hardware-in-the-loop simulation [45] presents a modelling approach to integrate hydraulic proportional spool valve to this hydraulic system. However, considering the slow dynamics in wind turbine and heat transfer, conventional proportional vale should meet the requirement of the system.

\section{CONCLUSION}

The sustainability of wind energy and other renewable energy sources continues to attract investment and development in the technologies. Of known wind energy harnessing technologies, Savonius turbine has considerable low power, limiting it to small power requirements applications.

Researches on the performance of Savonius rotor under various environmental conditions and design configurations has been documented. Using a simplified augmented turbine prototype, constant wind parameter over time and varied throttle orifice diameter, the optimum operation condition of the turbine yielding maximum turbine power and system thermal power output was found. The parameters at optimum condition corresponds to orifice diameter of $3 \mathrm{~mm}$, tip speed ratio of 1.2 and power coefficient of 0.2 . It is worth noting that no public information is made of the augmenters of the turbine prototype used. However, the power coefficient of the experimental rotor closely matches the output result of Wilson et. al work [17]. Optimum tip speed ratio was found to slightly differ.

Other than the torque coefficient and tip speed ratio parameters of the turbine, surface area of the turbine plays into its power output. This implies that efficient design materials for the turbine need be explored to improve on the weight per unit power output of the turbine.

To maintain optimum operating condition of the system, it is recommended to substitute the throttle valve in the setup with a solenoid actuated proportional valve to respond to the dynamic wind condition while keeping in mind the power requirement of additional control unit of the valve.

It was observed that a considerable amount of power (about $40 \mathrm{~W}$ ) was produced at minimum wind speed of 4 $\mathrm{m} / \mathrm{s}$. The compact design of this system and potential increase in power efficiency with increased surface area of turbine makes it suitable for remote application with high wind availability. Offshore room heating application presents a practical environment with high wind availability.

\section{REFERENCES}

[1] Herpiö, J. Simulation of Wind Powered Hydraulic Heating System. Lappeenranta: September 2014. Master's degree thesis. Lappeenranta University of Technology, School of Energy Systems. 48 p.

[2] Wortman, A. J. Introduction to Wind Turbine Engineering. National Bureau of Standards. Boston, Butterworth Publishers, 1983.

[3] Corbetta, G., Mbistrova, A. The European Offshore Wind Industry key trends and statistics 2014. January 2015. The European Wind Energy Association.

[4] McCrone, A. Global Trends in Renewable Energy Investment 2015. Frankfurt School - UNEP Collaborating Centre Frankfurt School of Finance \& Management. 16 p.

[5] Van der Hoeven, M. Wind Energy. Technology roadmap, 2013 edition. $58 \mathrm{p}$.

[6] Wind Turbine Paper. January 2012. AIMU Technical Services Committee. $24 \mathrm{p}$.

[7] Sun, Z., Tang, Z. Experimental Study on a Model of Bulk Wind
Energy Collecting System. Modern Applied Science, 2011. Vol. 5, No. 2, Pp. 143-148.

[8] Menghal, P. M., Laxmi, A. J. Real Time Control of Electrical Machine and Drives: A Review. International Journal of Advances in Engineering \& Technology, 2011. Vol. 1, Issue 4. Pp. 112-126.

[9] Bouscayrol, A. Hardware-in-the-loop (HIL) simulation. Lille: May 2009. University of Lille1, Sciences and Technology, L2EP, France.

[10]Pat. US4114809. Wind Powered Hydraulic Heating System. (Sampson, A. R.) Appl. US 804949, 1977-9-6. Publ. 1978-19-9. 6 p.

[11]Alia, M. A. K., Younes, T. \& Sarhan, H. Hydraulic Domestic Heating by Throttling. Journal of Scientific Research, 2010. Vol 2. Pp. 461- 465.

[12]Manyonge, A. W., Ochieng, R. M., Onyango, F. N. \& Shichikha, J. M. Mathematical Modelling of Wind Turbine in a Wind Energy Conversion System: Power Coefficient Analysis. Applied Mathematical Sciences, 2012. Vol. 6, 2012. Pp 4527 - 4536.

[13]Ragheb, M., Ragheb, A. M. Wind Turbines Theory - The Betz Equation and Optimal Rotor Tip Speed Ratio. In: Carriveau R., editor. Fundamental and Advanced Topics in Wind Power. InTech, 2011. Pp. $19-38$.

[14]Jones, B. Elements of Practical Aerodynamics, John Wiley and Sons, New York, United States, 1939. Pp. 8 - 41.

[15]Eldridge, F. R. Wind Machines. 2nd Edition. The MITRE Energy Resources and Environmental Series. Van Nostrand Reinhold Inc., U.S, 1980.

[16]Morshed, K. N. Experimental and Numerical Investigations on Aerodynamic Characteristics of Savonius Wind Turbine with Various Overlap Ratios. Statesboro: May 2010. Master's degree thesis. Graduate Faculty of Georgia Southern University. 66 p.

[17]Wilson, R. E. Lissaman, P. B. Applied Aerodynamics of Wind Power Machines. Aerovironment Inc, California, 1974.

[18]Letcher, T. Small Scale Wind Turbines Optimized for Low Wind Speeds. Published 2010.

[19]Weiss, S. B. (2010) Vertical Axis Wind Turbine with Continuous Blade Angle Adjustment. Massachusetts: May 2010. Bachelor degree thesis. Massachusetts Institute of Technology, department of Mechanical Engineering. 26 p.

[20]Sathyajith, M. Wind Energy Fundamentals, Resource Analysis and Economics. Springer Berlin Heidelberg, New York, 2006.

[21]Kloeffler, R. G., Sitz, E. L. Electric energy from winds. Kansas, the College, 1946.

[22]Modi, V. J., Fernando M. S. U. K. On the Performance of the Savonius Wind Turbine. Journal of Solar Energy Engineering, 1989. Vol. III, Pp. 71-81.

[23]Kamoji, M., Kedare, S. B. and Prabhu, S. Experimental Investigations on Single Stage Modified Savonius Rotor. Applied Energy, 2009. Vol. 86, Pp. 1064-1073.

[24]Ponomarev, P. Tooth-coil permanent magnet synchronous machine design for special applications. Lappeenranta: October 2013. Doctoral thesis. Lappeenranta University of Technology, School of Energy Systems. 111

[25]Ponomarev, P., Åman, R. and Handroos, H. High Power Density Integrated Electro- Hydraulic Energy Converter for Heavy Hybrid Offhighway Working Vehicles, Journal of IET Electrical Systems in Transportation, 2014. Vol. 4. Pp. 114-121.

[26]Puranen, J. Induction motor versus permanent magnet synchronous motor in motion control applications: a comparative study. Lappeenranta: December 2006. Doctoral Thesis, Lappeenranta University of Technology, School of Energy Systems. 147 p.

[27]Rotation Kinematics, Moment of Inertia, and Torque [web document]. [Referred 16.10.2015]. Available in PDF-file: http://bolvan.ph.utexas.edu/ vadim/Classes/14s/linang.pdf.

[28]Fluid Power Formula [web document]. [Referred 20.10.2015]. Available in PDF-file: http://hydraulicspneumatics.com/sitefiles/hydraulicspneumatics.com/files/archive/hydraulicspneumatics.com/ Content/Site200/ebooks/01_01_2006/80281Ch22IFPBFo_00000052653. pdf.

[29]Mahmoud, N., El-Haroun, A., Wahba, E. and Nasef, M. An Experimental Study on Improvement of Savonius Rotor Performance, Alexandria Engineering Journal, 2012. Vol. 51. Pp. 19-25.

[30]Hydraulics \& Pneumatics. Book 2, Chapter 18: Pressure-relief valves. [Referred 16.10.2015] Available at http://hydraulicspneumatics.com/other-technologies/book-2- chapter-18pressure-relief-valves 
[31]Fitch, E.C., Hong, I.T. Pressure Regulation. In: Fitch, E.C, Hong, I.T., editors. Hydraulic Component Design and Selection. Oklahoma: BarDyne, Inc., 1998. Pp. 205- 211.

[32]Juric, Z., Kulenovic, Z., Kulenovic, D. Influence of the hydraulic relief valve poppet geometry on valve performance. In: Proceedings of the 2010 TMT 14th International Research/Expert Conference; 2010 Sep 11-18; Mediterranean Cruise. Croatia: TMT, 2010. Pp. 517 - 520.

[33]Pat. US3514074. High Energy Loss of Fluid Control. (Self, R. E.) Appl. US 599229, 1968-6-6. Publ. 1970-6-26. 12 p.

[34]Flow Control Valve. 2015. [www.flutec.com]. Flutec 2015. [Referred 16.10.2015]. Available: http://www.flutecvalves.com/download/pdf/DV_DVP_DVE_valves.pdf.

[35]Manring, N. D. Hydraulic control systems. John Wiley and Sons, Inc., Hoboken, New Jersey, 2005.

[36]Tullis, J. P. Hydraulics of Pipelines: Pumps, Valves, Cavitation, Transients. John Wiley \& Sons, Inc., New York, 1989.

[37]Gear Type Flow meter VC. 2015. [www.krachtcorp.com]. Krachtcorp 2015. [Referred 16.10.2015] Available: http://www.krachtcorp.com/wpcontent/uploads/2012/05/VC_USA_02-12_view.pdf.

[38]Electronic Pressure Transmitter. 2015. [www.hydac.com]. hydac 2015. [Referred 16.10.2015] Available: http://www.hydac.com.au/MessageForceWebsite/Sites/279/Files/HDA38 00.pdf.

[39]Holman, J. P. Heat Transfer. McGraw-Hill Book Co. - Singapore, 1989.

[40]Oil/Air Cooler Units. [www. hydac.com]. hydac International [Referred 16.10.2015] Available: http://www.hydac.com.au/MessageForceWebsite/Sites/97/Files/e5806-102-05_oil-air- coolers-elc.pdf.

[41]Hydraulic Fluids Based on Mineral Oils and Related Hydrocarbons. [www.bosch.com]. Bosch Rexroth AG 2015. [Referred 16.10.2015] Available: http://dcamerica.resource.bosch.com/media/us/products_13/product_groups_1/in dustrial_hydra ulics_5/pdfs_4/re90220.pdf.

[42]Bartz, W. J. Synthetic Hydraulic Fluids for High Performance Applications. Proceedings of the National Conference on Fluid Power, 2000. Vol. 48. Pp. 7-20.

[43]Ultramax HVLP 46 oil. [www.valvolineeurope.com]. Valvoline. [Referred 16.10.2015] Available: http://www.valvolineeurope.com/english/products/hydraulic_oils/cid\%28 9180\%29/ultr amax_hvlp_46.

[44]Hydraulic Fluids. [www.parker.com]. Parker Hannifin GmbH \& Co. KG. [Referred 16.10.2015] Available: http://www.parker.com/Literature/Germany/CD_Rom\%20Bauteilfreigab eliste\%20Mec hanik\%20Hydraulik\%20UK/general-fluids_UK.pdf

[45]Ferreira, J. A., Almeida, F. G. D., Quintas, M. R. Semi-empirical Model for a Hydraulic Servo-solenoid Valve. Journal of Systems and Control Engineering, 2002. Vol. 216. Pp. 237-248.

[46]Windside WS $4 B$ / WS $4 A$ [www.windside.com]. Windside [Referred 16.10.2015] Available: http://www.windside.com/filebank/141- WS4BEng2010.pdf. 